\title{
HORNOS FORRAJEROS: UNA TECNOLOGÍA PROMISORIA PARA PEQUEÑAS FINCAS GANADERAS DEL TRÓPICO SECO. ASPECTOS PRÁCTICOS1
}

\author{
Romeo Solano ${ }^{2}$, Roberto Ruano ${ }^{3}$, Reyna Zamora 4
}

\begin{abstract}
RESUMEN
Hornos forrajeros: Una tecnología promisoria para pequeñas fincas ganaderas del trópico seco. El presente trabajo fue realizado en diferentes fincas del trópico seco de Nicaragua. Las experiencias se llevaron a cabo principalmente en los municipios de Estelí, Somoto, Condega, Pueblo Nuevo y Limay, área de cobertura del Proyecto PRONORTE. En esta región se presenta una precipitación pluvial de alrededor de 600 a $900 \mathrm{~m}$ con una distribución errática, y una época seca muy marcada y con fuertes deficiencias en la disponibilidad de alimentos para el ganado. Los hornos forrajeros fueron construidos con la participación de los productores, quienes fueron informados de los pormenores de la tecnología a efecto de que la experiencia fuera conducida en calidad de validación. Los costos de $\mathrm{kg}$ de materia seca del forraje del horno forrajero fue de $\$ 0,05$ lo que lo hace asequible a los productores de la región, además de utilizar residuos de las cosechas de granos básicos que de otra manera perderían calidad y cantidad. La aceptabilidad de los hornos forrajeros fue alta (100\%) y la adopción alcanzó el 96\%, cifras que indican que esta tecnología es apropiada y adaptada a las condiciones socioe-conómicas de los productores de la región seca del norte de Nicaragua. .
\end{abstract}

\begin{abstract}
Fodder kilns: a new promissing technology for smaIl dairy farms of the dry tropics. The present work was conducted on different farms of the dry tropics of Nicaragua. The experience was obtained mainly in the municipalities of Esteli, Somoto, Condega, Pueblo Nuevo and Limay, which is the area covering the PRONORTE Project. This region is characterized by an irregular rainfall distribution which varies from 600 to $900 \mathrm{~mm}$ and a heavy marked dry season with strong shortages of cattle feed. The fodder kilns were built by the farmers, who were informed in detail on the technology used, so this expcrience was considered as a validation. The cost of dry fodder for the kiln was $\$ 0.05 / \mathrm{kg}$, which is readily available to the producers of the region, besides of the use of basic grains' residues, that otherwise would lose their quality and quantity. The acceptability of the fodder kilns was high (100\%) and its adoption reached $96 \%$, which means that this technology is appropriate and could be adapted to the socioeconomic conditions of the producers from the dry region of northern Nicaragua.
\end{abstract}

\section{INTRODUCCION}

El sistema de producción ganadera de doble propósito, tradicional en las fincas con escasos recursos económicos en el trópico seco de América Central, se enfrenta a la mayor escasez forrajera durante la época seca, la cual se extiende en algunas regiones, hasta nueve meses al año.
El manejo tradicional de los pastizales provoca que durante la época de lluvias exista un excedente de pastos que generalmente se desperdicia en un alto porcentaje, debido a formas inadecuadas de manejo bajo pastoreo. Se utilizan cargas que ante la ausencia de un sistema de rotación controlada de los potreros, resulta un uso poco eficiente del pasto (Solano, 1986).

\footnotetext{
1 Presentado en la XXXIX Reunión Anual del PCCMCA en Guatemala, América Central.

2 Líder Proyectos Agroforestales CA TIE-SAREC.

3 Catedrático de la Escuela de Zootecnia de la USAC, Guatemala.

4 Jefe de Producción de Pastos del MAG-Región I de Nicaragua.
} 
La época seca, por el contrario, exhibe escasa o nula recuperación de los pastizales y el ganado es alimentado hasta donde es posible, con residuos de cosecha, los que también son manejados en condiciones poco tecnificadas.

La recolección de forrajes y residuos de cosechas durante la época de abundancia con el fin de almacenarlos, utilizando tecnologías adaptadas a las condiciones socioeconómicas correspondientes a las circunstancias y realidad de los pequeños ganaderos, ha sido una preocupación para algunos profesionales de las ciencias agropecuarias, que han dedicado el ejercicio de su profesión a trabajar en la generación y validación de tecnologías que cumplan con las características de responder a la solución de las necesidades del productor y su familia; y que al ser llevadas a su finca, estas posibles soluciones surjan del enfoque de sistemas de abajo hacia arriba y que lleven la potencialidad de altos índices de adopción (Solano, 1986).

Una de estas tecnologías es la del horno forrajero, la que debido a su sencillez, sentido práctico y bajos costos, ha sido introducida por los autores, a los sistemas de producción ganadera, en pequeñas fincas desde 1979 (Ruano, 1980; Solano, 1984).

Durante los últimos cinco años, el Centro Agronómico Tropical de Investigación y Enseñanza (CATIE), proporcionó asesoria técnica al proyecto PRONORTE de Nicaragua, que fue diseñado con la finalidad de generar, validar y transferir tecnología para productores de escasos recursos económicos, con fincas pequeñas o cooperativas del trópico seco de la Región I de Nicaragua (Esteli, Somoto, Condega, Pueblo Nuevo y Limay) (Solano y Valdivia, 1989a).

Basados en las experiencias de trabajos realizados con el equipo de técnicos nacionales del Ministerio de Agricultura de la Región 1 de Nicaragua, los autores presentan experiencias obtenidas en la introducción de los hornos forrajeros, al sistema de producción de pequeños ganaderos del trópico seco de Guatemala y Nicaragua.
A continuación se ofrece una descripción del horno forrajero.

\section{COMO ELABORAR UN HORNO FORRAJERO}

\section{Selección del terreno}

La selección del terreno donde se construirá el horno forrajero deberá corresponder preferiblemente a una elevación topográfica con pendiente suave y con suelos de textura arcillosa o franco arcillosa, con la finalidad de que las paredes de la fosa queden fuertemente definidas y se evite al máximo la infiltración de humedad hacia el material almacenado con el consiguiente aumento en el porcentaje de pérdidas.

\section{Construcción de la fosa}

Con la finalidad de propiciar la mayor y mejor compactación posible, la fosa debe ser de forma trapezoidal con las dimensiones en concordancia con la cantidad de forraje que se necesite almacenar, para un determinado periodo de tiempo.

\section{Llenado del horno forrajero}

El forraje de maíz cosechado en el estado fisiológico de capa negra u otro forraje se transporta a la fosa, la cual deberá estar debidamente revestida con cañas de maíz, palma u otro material disponible en la región; el material forrajero se coloca en forma longitudinal, paralelo al eje mayor de la fosa, en capas no mayores de $20 \mathrm{~cm}$, tratando de que las plantas queden coincidiendo puntas con troncos suavemente traslapadas, para lograr una mayor compactación y eliminar al máximo cámaras de aire que reducirán la calidad del forraje (Figura 1).

Cada capa de forraje deberá ser sometida a una fuerte compactación cuidando de que las esquinas queden llenas de material para eliminar las cámaras de aire que allí se forman. 
Cuando el horno se ha llenado completamente, deberá cubrirse con una fuerte capa de forraje y sobre este una gruesa capa de tierra, las cuales deberán compactarse lo mejor posible para asegurar que el material forrajero quede sin cámaras de aire y protegido de cualquier ingreso de agua de escorrentía. La capa de tierra de la cubierta exterior deberá tener un espesor de $75 \mathrm{cms}$ a 1 metro, bien compactada y es conveniente regarla durante tres días consecutivos con la finalidad de favorecer la compactación y la impermeabilidad.

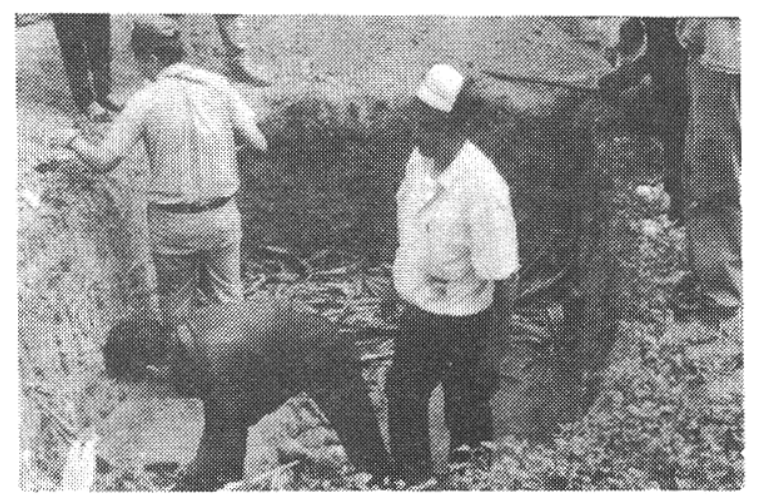

Figura 1. Llenando un horno forrajero (Limay, Nicaragua, 1991).

\section{Cálculo del horno forrajero}

Se aconseja la forma trapezoidal, con las dimensiones que son necesarias para almacenar el forraje necesario para el número de animales y días que se estimen convenientes. Es aconsejable considerar un 5\% de desnivel longitudinal para propiciar el drenaje interior y rodear la estructura con zanjas de drenaje, para así evitar que el agua de escorrentía entre a la fosa y ocasione mayores pérdidas por excesiva humedad.

Las paredes de la fosa deben cubrirse con una capa no menor de $10 \mathrm{~cm}$, con el mismo material que se va a almacenar, o bien con un lienzo de polietileno, si es posible. El fondo de la fosa debe quedar perfectamente cubierto y debe construirse un drenaje longitudinal para propiciar la expulsión del agua que desprenda el material almacenado.
El cálculo del volumen del horno se realiza de la siguiente manera:

$((\mathrm{B}+\mathrm{b}) / 2)^{*} \mathrm{~h}=$ área Luego: área * longitud=volumen de la fosa.

donde:

$$
\begin{aligned}
& \mathrm{B}=\text { Base mayor } \\
& \mathrm{b}=\text { Base menor } \\
& \mathrm{h}=\text { Altura }
\end{aligned}
$$

Para llenar el horno forrajero se puede utilizar forraje verde proveniente de barreras vivas, residuos de cosechas y pasto jaragua (Hyparrhenia ruja), el cual es común en la región centroamericana, (Figura 2).

Si se considera el pasto jaragua con un contenido del $20 \%$ de materia seca, se puede ver el siguiente ejemplo.

Para $5 \mathrm{t}$ de materia seca $=\mathrm{xt}$ de materia verde $* 0,20$, es igual a $25 \mathrm{tm}$ de forraje verde (donde $\mathrm{x}=5 / 0,2$ ), a esta cantidad se le adiciona el $10 \%$ de pérdidas esperadas por pudrición y el $10 \%$ por desperdicio del ganado, al momento de ser ofrecido y consumido en el corral; por lo tanto, tenemos: $25 * 0,20=5 \mathrm{t}$ de materia verde adicionales, para un total de 30 toneladas de forraje verde.

Si se considera una densidad del forraje guardado de $600 \mathrm{~kg} / \mathrm{m}^{3}$ y una fosa de $2,5 \mathrm{~m}$ de base mayor, $2 \mathrm{~m}$ de base menor y $1 \mathrm{~m}$ de profundidad, necesitamos un horno de $50 \mathrm{~m}^{3}(\mathrm{~V}=30 / 0,6)$ de volumen, de tal manera que el largo será: $2,25 \mathrm{~m}^{2 *} 1=50 \mathrm{~m}^{3}$,

donde: $1={\underline{50 \mathrm{~m}^{3}}}^{2}=22,2$ metros, lo que equivale a: $2,25 \mathrm{~m}^{2}$

Largo $=(30 / 0,6) / 2,25=22,2$ metros.

$$
\mathrm{B}=2,50
$$

$\mathrm{h}=\mathrm{l}$ 


$$
\begin{aligned}
& \mathrm{a}=(2,5+2) \times 1=2,25 \mathrm{~m}^{2} \\
& 2 \\
& \begin{array}{ll}
\mathrm{l}=\mathrm{v} & \mathrm{v}=\text { volumen } \\
\mathrm{a} & \mathrm{a}=\text { área }
\end{array} \\
& 1=\frac{50}{2,25}=22,2 \mathrm{~m}
\end{aligned}
$$

Por lo anterior, puede generalizarse la siguiente igualdad:

$$
\begin{array}{ll}
\mathrm{m}^{2 *} \mathrm{~lm}=\mathrm{tm} / \mathrm{d} & \\
\text { donde: } & \mathrm{m}^{2}=\text { área del trapecio } \\
& 1=\text { largo de la fosa } \\
& \mathrm{d}=\text { densidad } \\
& \mathrm{tm}=\text { toneladas de materia verde }
\end{array}
$$

De la fórmula anterior puede despejarse cualquier incógnita.

El cálculo de horno y conos forrajeros se presentan con más amplitud en Solano y Morales, 1990.

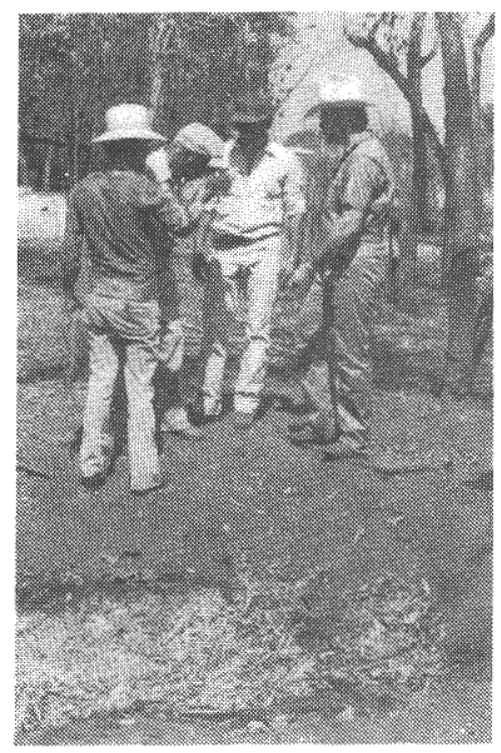

Figura 2. Fosa del horno forrajero, listo para llenarse (Nueva Concepción, Guatemala, 1984).

\section{Selección del material por almacenar}

En la Región I de Nicaragua, durante los años 1990 y 1991, debido a la escasez de lluvias registradas durante el invierno, la producción de granos básicos se perdió en aproximadamente el $80 \%$, razón por la cual las experiencias que aquí se describen corresponden a forraje de maíz; sin embargo, cualquier forraje disponible es bueno para llenar el horno forrajero y disponer de forraje en la época de escasez.

Cuando es posible obtener buenas cosechas, al momento de la dobla del maíz, conviene cortar la punta de la planta y utilizar ésta para almacenada en el horno forrajero. Con esta práctica es posible recolectar de 7-8 tm/ha de materia seca (Solano y Elvira, 1986; Solano, Rodríguez y Elvira, 1986).

Para las condiciones de la Región 1 de Nicaragua, no se recomienda la utilización de la planta de maíz completa, incluyendo la mazorca con grano, debido a que la producción esperada de leche del ganado predominante en las pequeñas fincas de América Central, es tan pequeña (2-4 1/ día) que no llegarían a compensar los costos de oportunidad del grano de maíz que no vendería el agricultor. Solano y Valdivia (1989), estimaron que fincas ganaderas de Limay no producen ninguna utilidad económica para el agricultor, bajo condiciones del sistema tradicional donde se calculó un ingreso neto negativo. Sin embargo, en Somoto, Ocotal y Estelí, donde se implementaron prácticas de conservación de forrajes y alimentación de verano, la rentabilidad fue positiva.

\section{Cambios biológicos y químicos que sufre el pasto almacenado}

El horno forrajero tiene mucha menor cantidad de cambios que el ensilado; sin embargo, se presentan: una fase aeróbica y una anaeróbica. El proceso se completa durante tres a cuatro semanas.

\subsection{Actividad aeróbica}

Las células vivas de la planta forrajera siguen respirando y consumiendo oxígeno del aire del silo, produciendo anhídrido carbónico, agua y liberando energía. 
Simultáneamente aparecen y se multiplican bacterias, hongos y levaduras. En esta fase, la temperatura se eleva alrededor de $37^{\circ} \mathrm{C}$.

\subsection{Actividad anaeróbica}

Cuando se ha consumido todo el oxígeno del aire del horno, las bacterias anaeróbicas, principalmente las acidificadoras y proteolíticas se multiplican a un ritmo vertiginoso. Al mismo tiempo, los hongos y las levaduras mueren por no soportar $\mathrm{pH}$ muy bajos, pero continuando como sistemas enzimáticos que generan alcoholes y otros productos finales. La actividad anaeróbica origina las siguientes transformaciones:

a) Los hidratos de carbono y en especial los azúcares se descomponen y forman ácido láctico, algo de ácido acético y algunos otros ácidos y alcoholes.

b) Parte de las proteínas se descomponen y forman aminoácidos y aminas.

c) La acidez llega finalmente a una intensidad tal que hasta las mismas bacterias mueren y el proceso queda así completado. Al alcanzar este punto, el forraje almacenado en un buen horno, permanecerá indefinidamente, pero si se expone a la acción del aire, los microorganismos reanudarán su actividad.

d) $\mathrm{pH}$ óptimo. Un pH de 3,5-4 es la clave de una buena conservación del material porque impide el desarrollo de las bacterias, incluyendo las que producen la descomposición y la putrefacción.

e) La presencia de pequeñas cantidades de alcohol etílico y otros es aconsejable, ya que se combinan con los ácidos para formar compuestos que dan al ensilado su olor característico.

f) Si se les corta con el grado conveniente de madurez, el forraje de maíz y de millón (sorgo criollo), tienen la cantidad necesaria de azúcar como para obtener un buen producto. Para obtener un ensilado de gramíneas de buena calidad se les deberá secar hasta que el contenido de humedad se reduzca al $67 \%$. El contenido de humedad es otro de los factores importantes para determinar la calidad. El forraje que contiene más del $67 \%$ de humedad es dificil de manipular y probablemente origina un material viscoso y pútri- do, a causa de la presencia de ácido butírico y otros ácidos indeseables.

\section{Cómo determinar el contenido de humedad}

Con un poco de práctica, los ganaderos podrán determinar en qué momento el forraje se ha secado lo suficiente y cuando el contenido de humedad está entre el 62 y el $67 \%$. Dentro de todos los métodos que existen, el que más se menciona es el de la compresión, el cual consiste en tomar una muestra de forraje, picarlo, hacerle presión con las manos y observar las siguientes manifestaciones (Harvard, 1978):

a) Si el jugo corre libremente entre los dedos, el cultivo contiene entre 75 y $85 \%$ de humedad. Si la bola de forraje mantiene su forma y la mano queda húmeda, el forraje contiene entre 70 y $75 \%$ de humedad.

b) Si la bola de forraje se expande lentamente y la mano no se humedece, el forraje contiene entre el 62 y $67 \%$ de humedad. Este es el estado ideal para con se vario sin ningún tratamiento.

c) Si la bola de forraje se deshace al abrir la mano, el forraje contiene menos del $62 \%$ de humedad. Solamente los pastos muy tiernos se pueden conservar a esta humedad.

\section{Densidades de algunos forrajes}

\section{a) Maíz (Zea mays)}

Un metro cúbico de horno forrajero se llena con 270 $\mathrm{kg}$ de materia verde, cuando la mazorca se encuentra en estado de capa negra (camagua), estado fisiológico que coincide con la dobla de la planta. Esta cantidad de forraje se obtiene de un área de $155 \mathrm{~m}^{2}$, cuando el cultivo se siembra a una distancia de $70 \mathrm{~cm}$ entre surcos y $50 \mathrm{~cm}$ entre plantas, con posturas de dos a tres granos cada una. En términos generales se puede estimar que una hectárea de maíz produce $17 \mathrm{t}$ de forraje, que pueden ser almacenadas en $63 \mathrm{~m}^{3}$ de hornos (Ruano, 1980). Estas producciones coinciden 
con las calculadas por Solano y Elvira (1986) en cultivos de maíz de primera, mientras que en el ciclo de segunda la producción fue de 7,48 tm/ha con el $40 \%$ de materia seca (Solano, Rodríguez y Elvira, 1986).

\section{b) Maicillo o Millón (Sorghum vulgare)}

Cuando el cultivo es asociado con maíz y sembrado en la época de segunda, se necesitan $300 \mathrm{~kg}$ de forraje de sorgo (una vez cosechada la panoja), para llenar un metro cúbico de horno forrajero. Esta cantidad de forraje se obtiene de $406 \mathrm{~m}^{2}$. Lo anterior equivale a una producción de 15 toneladas por hectárea, que pueden almacenarse en $50 \mathrm{~m}^{3}$ de hornos forrajeros (Ruano, 1980).

\section{c) Napier (Pennisetum purpureum)}

Se necesitan $350 \mathrm{~kg}$ de forraje verde de napier (pasto elefante), para llenar un metro cúbico de horno forrajero, cuando este se encuentra a una altura entre 1,50 y $1,70 \mathrm{~m}$, esta producción se obtiene de $210 \mathrm{~m}^{2}$, cuando el napier ha sido sembrado a $50 \mathrm{~cm}$ entre surcos y la caña se ha sembrado en cadena simple sobre el surco.

Bajo estas condiciones del cultivo es posible obtener una producción de 17 toneladas de forraje verde, por hectárea, por corte. Bajo condiciones de trópico seco es posible obtener cuatro cortes al año (Ruano, 1980). Producciones mayores fueron obtenidas por Solano, Rodríguez y González (1986) en Nueva Concepción, Guatemala, donde el napier cortado cada 60 días sin fertilización y sembrado por estacas, produjo $134 \mathrm{t} / \mathrm{ha} / \mathrm{año}$ con el $21 \%$ de materia seca y 1,34 de proteína cruda.

\section{d) Caña japonesa (Saccharum sinensis)}

Cuando el cultivo se encuentra a una altura de 1,70 $\mathrm{m}$, aproximadamente, se necesitan $430 \mathrm{~kg}$ de forraje verde para llenar un metro cúbico. Esta producción es posible obtenerla de 68 metros cuadrados, cuando el cultivo se ha sembrado a un metro entre surcos y con cadena simple, sobre el surco. La hectárea produce aproximadamente 63 toneladas en un solo corte (Ruano, 1980).

\section{Apertura del horno forrajero y calidad del forraje}

Después de que los cambios químicos y biológicos han sucedido, el material forrajcro puede permanecer almacenado en forma indefinida, siempre y cuando no se exponga al aire.

Experiencias obtenidas por Ruano (1980), en la Estación Pecuaria de Petapilla de DIGESEPE, en Chiquimula, Guatemala, indican que cuando se separó la cubierta de tierra del horno (de $1 \mathrm{~m}$ de espesor) en un área suficiente para extraer el forraje necesario para un día de alimento de los animales, se obtuvo un material de las siguientes características (en hornos llenados con maiz):

a) Un forraje de color verde amarillento pálido, jugoso, palatable.

b) Olor agradablemente muy semejante al de la melaza de caña de azúcar.

c) Composición química del forraje.

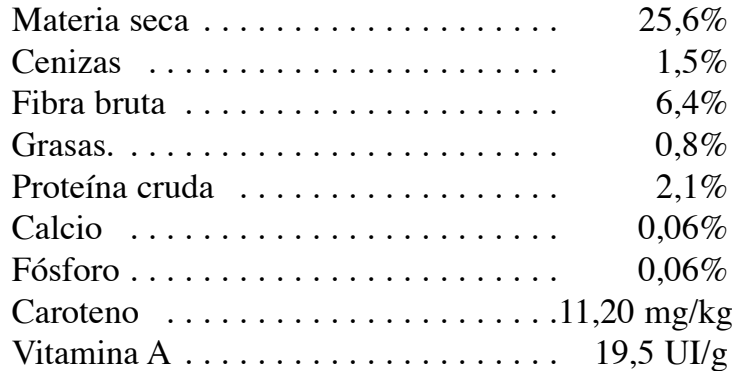

\section{Costos del forraje almacenado en hornos}

En las experiencias realizadas por el Proyecto PRONORTE, en Somoto, Región I de Nicaragua, localidad representativa del trópico seco, se elaboraron varios hornos forrajeros de diferentes dimensiones y como promedio se obtuvieron los siguientes costos expresados en dólares americanos (Solano y Valdivia, 1991):

Excavación del hoyo . . . . . . . . . $\quad 7,50$

Corte rastrojo de maíz $\ldots \ldots \ldots \ldots$. . . $\quad 9,00$

Acarreo del rastrojo . . . . . . . . . . 14,00

Llenado y apisonado . . . . . . . . . . $\quad 7,50$

Tapado . . . . . . . . . . . . 1,50 
Precio del rastrojo (oportunidad) . . . . .

Total ..................

Costo por kg de materia seca: $\$ 0,0545$

En cinco hornos, se utilizaron plantas de maíz con pocas mazorcas que lograron carga parcial, debido a la fuerte sequía del año que ocasionó la pérdida casi total $(80 \%)$ de la cosecha de maíz de la zona. El follaje de maíz tenía $40 \%$ de materia seca y el horno se llenó con $2614,5 \mathrm{~kg}$ de materia verde, 10 que equivale a $1045,8 \mathrm{~kg}$ de materia seca. Las dimensiones de los hornos fueron: $\mathrm{B}=2,3 \mathrm{~m}, \mathrm{~b}=$ $1,8 \mathrm{~m}, \mathrm{~h}=1,2 \mathrm{~m} \mathrm{~h}$ y $1=3,4 \mathrm{~m}$, para un volumen de 8,36 $\mathrm{m}^{3}$. La densidad del forraje fue de $312,7 \mathrm{~kg} / \mathrm{m}^{3}$ de forraje traido del campo y de $125,10 \mathrm{~kg} / \mathrm{m}^{3}$ de materia seca.

\section{Ventajas generales del horno forrajero}

a) El producto final del horno forrajero es de muy buena calidad y tan bueno como el proveniente de cualquier otra forma de almacenamiento de forrajes.

b) El horno puede ser llenado durante la época de lluvias, especialmente en la canícula y el material no sufre ningún daño, pudiendo permanecer almacenado por largos períodos de tiempo.

c) El forraje es consumido con mucha aceptación por los bovinos.

d) El proceso es sumamente sencillo, económico y está al alcance de los productores más modestos del istmo centroamericano.

\section{Aceptabilidad y adopción del horno forrajero}

Las pruebas hechas por los autores en Nicaragua y Guatemala, presentaron un $100 \%$ de aceptabilidad y $96 \%$ de adopción*. Esta práctica también ha tenido aceptación institucional al haber sido adoptada por el Ministerio de Agricultura de la Región 1 como una estrategia para combatir la escasez de forraje en la época seca en esa Región. Proyectos de validación como el de Sis temas Agrosilvopastoriles del CATIE en Centro América, financiado por la Agencia Canadiense de Desarrollo, lo estó implementando en los países de su cobertura. La Dirección General de Servicios Pecuarios de Guatemala (DIGESEPE) también lo ha introducido en fincas ganaderas; y otros proyectos como el de GTZ-CATIE en Puriscal, Costa Rica, han hecho pruebas con árboles forrajeros, bajo la asesoría de uno de los autores de estas experiencias.

\section{LITERATURA CITADA}

HARVARD, D. 1978. Las plantas forrajeras tropicales, técnicas agrícolas y producciones tropicales. Ed. Blume, Barcelona.

RUANO, R. 1980. Conservación de pasto en hornos forrajeros (Boletín técnico, en prensa).

SOLANO, R.A. 1984. Generación y validación de un sistema mejorado de producción animal en Nueva Concepción, Guatemala. Informe Convenio ICTA-CATIE-ROCAP. Guatemala.

1986. Desarrollo de un sistema mejorado de producción mixta en Nueva Concepción, Guatemala. CA TIE. Serie Técnica. Informe Técnico No. 103. 65 p.

.; ELVIRA, P.G. 1986. Producción combinada granoforraje en el cultivo de maíz en siembra de fuego. In Investigación en componentes en apoyo al desarrollo de la alternativa mejorada para el sistema mixto en Nueva Concepción, Guatemala. CATIE. Serie Técnica. Informe Técnico no. 96. p. 57-64.

; RODRIGUEZ, A.; ELVIRA, P. G. 1986. Producción combinada grano-forraje de maíz en siembra de segunda. In: Investigación en componentes en apoyo al desarrollo de la alternativa mejorada para el sistema mixto en Nueva Concepción, Guatemala. CATIE. Serie Técnica. Informe Técnico W 96. p.57-64.

; RODRIGUEZ, A.; GONZALEZ, H. 1986. Evaluación de algunas prácticas agronómicas para el establecimiento y manejo de napier (Pennisetum purpureum, Schumack) en Nueva Concepción. In Investigación en componentes en apoyo al desarrollo de la alternativa 
mejorada para el sistema mixto en Nueva Concepción, Guatemala. CATIE. Serie Técnica. Informe Técnico no. 96. p. 33-40.

; VALDIVIA, E. 1989. Informe de Labores del Proyecto de Desarrollo Rural Integrado (PRONORTE). Junio 1987-Mayo 1989. Turrialba, Costa Rica, CATIE. $16+53$ p.
; VALDIVIA, E. 1989a. Identificación y Caracterización de los Agrosistemas Predominantes y Dominios de Recomendación del Trópico Seco de la Región I, Nicaragua. Convenio CATIE-PRONORTE. Turrialba, Costa Rica, CATIE. 192 p.

; VALDIVIA. 1991. Informe de Labores del Convenio CATIE/PRONORTE, Junio 1989-Diciembre 1990. Turrialba, Costa Rica, CATIE. 